\title{
Allicin protects traumatic spinal cord injury through regulating the HSP70/Akt/iNOS pathway in mice
}

\author{
SHUNYI WANG and DONGLIANG REN \\ Department of Orthopedics, The First Central Hospital of Baoding, \\ Baoding, Hebei 071000, P.R. China
}

Received June 14, 2015; Accepted June 7, 2016

DOI: $10.3892 / \mathrm{mmr} .2016 .5651$

\begin{abstract}
Allicin is a major component of garlic, extracted as an oily liquid. The present study was designed to investigate the beneficial effects of allicin on traumatic spinal cord injury (TSCI) in mice, and whether the effects are mediated via regulation of the heat shock protein 70 (HSP70), v-akt murine thymoma viral oncogene homolog 1 (Akt) and inducible nitric oxide synthase (iNOS) pathways. Adult BALB/c mice (30-40 g) received a laminectomy at the T9 vertebral level as a model of TSCI. In the present study, treatment of the TSCI mice with allicin significantly increased their Basso, Beattie and Bresnahan $(\mathrm{BBB})$ scores $(\mathrm{P}<0.01)$ and reduced the spinal cord water content $(\mathrm{P}<0.01)$. This protective effect was associated with the inhibition of oxidative stress and inflammatory responses in TSCI mice. Western blot analysis demonstrated that allicin increased the protein levels of HSP70, increased the phosphorylation of Akt and reduced the iNOS protein expression levels in TSCI mice. Additionally, treatment with allicin significantly reduced the levels of ROS and enhanced the NADH levels in TSCI mice. Collectively, these data demonstrate that the effects of allicin on TSCI are mediated via regulation of the HSP70, Akt and iNOS pathways in mice.
\end{abstract}

\section{Introduction}

With high incidences of disability and other serious consequences, traumatic spinal cord injury (TSCI) can result in catastrophic damage to patients (1). Direct or indirect insult to the backbone and spinal cord can lead to TSCI, which subsequently affects the daily life of the patient and their family members (2). TSCI morbidity is higher in developed countries compared with developing countries. The USA mortality rate is $20-45 / 100,000$, and the rate of TSCI occurrence

Correspondence to: Dr Shunyi Wang, Department of Orthopedics, The First Central Hospital of Baoding, 320 Changcheng North Road, Baoding, Hebei 071000, P.R. China

E-mail: wangshunyibd@163.com

Key words: allicin, traumatic spinal cord injury, HSP-70, Akt, iNOS is $900 / 100,000$ (3). Advancements to the transportation, construction and mining industries have increased the incidence of TSCI in China. The morbidity rate of TSCI caused by earthquake disasters has reached $10 \%$. Survey data from the population of Beijing in 2005 indicated that the rate of TSCI was $60.2 / 100,000(4)$.

Due to serious complications, patients with TSCI may require long periods of hospitalization. The TSCI clinical pathway, a standardized method of patient care following TSCI, has achieved great success (5). Multidisciplinary investigation was used to develop a clinical pathway for a standardized model of TSCI treatment. Following a 6-month trial period, the clinical pathway reduced the length of patient hospitalization and the total costs (6). The TSCI clinical pathway has various advantages and lasting influences on the overall quality of TSCI treatment. The pathway reinforces to health professionals that rehabilitation and nursing at the acute phase of TSCI are inseparable (7). Additionally, the diagnosis of TSCI is clear, the surgical invention is uniformed and the complications are predictable. It is important to formulate a similar standardized clinical pathway for the treatment of patients with TSCI in China (8).

Allicin is a major component of garlic. Previous studies have demonstrated that allicin has important health benefits and medicinal effects (9). Allicin has been demonstrated to inhibit the growth of pathogenic microorganisms, including certain bacteria, viruses and fungi, and to inhibit tumor growth $(10,11)$. Additionally, it can prevent arteriosclerosis, stenocardia, cerebral infarction, arrhythmia and hydrargyrism. Allicin can also can reduce cholesterol and blood pressure, regulate blood sugar levels, enhance the immune system and reduce oxidation (12). Therefore, the aim of the present study was to investigate the use of allicin in TSCI, and to elucidate whether the effects of allicin are mediated by the heat shock protein 70 (HSP70), v-akt murine thymoma viral oncogene homolog 1 (Akt) and inducible nitric oxide synthase (iNOS) pathways.

\section{Materials and methods}

Animals, surgery and experimental groups. Adult BALB/c mice ( $\mathrm{n}=40 ; 30-40 \mathrm{~g}$ ) were obtained from The First Central Hospital of Baoding (Baoding, China). The mice were housed at $24 \pm 1^{\circ} \mathrm{C}$ and maintained on a $12: 12 \mathrm{~h}$ light/dark cycle. The 
mice were provided with ad libitum access to food and water. All experimental protocols were approved by the Institutional Animal Care and Use Committee of The First Central Hospital of Baoding and performed in accordance with the National Institutes of Health Guide for the Care and Use of Laboratory Animals.

All experimental mice were anesthetized by ketamine (100 mg/kg; Sinopharm Chemical Reagent Co., Ltd., Shanghai, China) and xylazine $(10 \mathrm{mg} / \mathrm{kg}$; Sinopharm Chemical Reagent Co., Ltd.) injection via the caudal vein. The mice were randomly assigned into five experimental groups ( $\mathrm{n}=8$ in each group), as follows: Sham group; TSCI group; $1 \mathrm{mg} / \mathrm{kg}$ allicin group; $10 \mathrm{mg} / \mathrm{kg}$ allicin group; and $50 \mathrm{mg} / \mathrm{kg}$ allicin group. Allicin (National Institute for the Control of Pharmaceutical and Biological Products, Beijing, China) and saline were delivered via intraperitoneal injection. The anesthetized mice, excluding the sham group, received a laminectomy at the T9 vertebral level using the Infinite Horizons impactor (75 kdyn; Precision Systems and Instrumentation, LLC, Fairfax Station, VA, USA). Following TSCI, all mice were housed in warmed cages at $35-37^{\circ} \mathrm{C}$. The mice received either 1,5 or $10 \mathrm{mg} / \mathrm{kg}$ allicin. Sham and TSCI mice received $2 \mathrm{ml}$ sterile saline.

Locomotor recovery and the spinal cord water content. Mice were relocated to the test environment $(90 \times 4 \mathrm{~cm})$ where Basso, Beattie and Bresnahan (BBB) testing was performed prior to and 1 week following TSCI. BBB scores range from 0 (no observable hind-limb movements) to 21 (normal gait). Following sacrifice by cervical dislocation under anesthesia, the spinal cord samples were collected, weighed, recorded and dried at $80^{\circ} \mathrm{C}$ for $48-72 \mathrm{~h}$. The spinal cord water content was calculated using the following formula: [(Wet weight - dry weight)/wet weight] x 100 .

Enzyme-linked immunosorbent assay for markers of oxidative stress and inflammation. Briefly, the spinal cord samples were collected and homogenized, and the supernatant was collected by centrifugation at $12,000 \mathrm{x} \mathrm{g}$ and resuspended in lysis buffer containing protease inhibitors (Beijing Biosynthesis Biotechnology Co., Ltd., Beijing, China). The supernatant was collected and the protein concentration was measured using a bicinchoninic acid (BCA) assay kit (Cell Biolabs, Inc., San Diego, CA, USA). The activities of catalase (CAT; \#707002), superoxide dismutase (SOD; \#706002), nuclear factor- $\kappa \mathrm{B}$ $(\mathrm{NF}-\kappa \mathrm{B} ; \# 10007889)$ and tumor necrosis factor- $\alpha$ (TNF- $\alpha$; \#500850) were measured using commercially available assay kits (Cayman Chemical Company, Ann Arbor, MI, USA) following the manufacturer's protocol.

Western blot analysis. Briefly, the spinal cord samples were homogenized, and the supernatant was collected and harvested in lysis buffer containing protease inhibitors. The protein concentration was measured using the BCA protein assay kit. Protein samples $(\sim 60 \mu \mathrm{g})$ were separated by $10 \%$ SDS-PAGE and transferred onto a polyvinylidene difluoride membrane (Bio-Rad Laboratories, Inc., Hercules, CA, USA). The membrane was blocked with 5\% non-fat milk and incubated with the following primary antibodies, purchased from Santa Cruz Biotechnology, Inc. (Dallas, TX, USA), at $4^{\circ} \mathrm{C}$ for $10-12 \mathrm{~h}$ : Rabbit polyclonal phosphatidylinositol-4,5-bisphosphate 3-kinase (PI3K; 1:800; cat. no. sc-67306); rabbit polyclonal Akt (1:500; cat. no. sc-8312); rabbit polyclonal phospho-Akt (1:500; cat. no. sc-135650); rabbit polyclonal iNOS (1:500; cat. no. sc-8309); and rabbit polyclonal $\beta$-actin (1:600; cat. no. sc-130656). Membranes were then washed with Tris-buffered saline-Tween 20 and incubated for $2 \mathrm{~h}$ at room temperature with goat anti-rabbit secondary antibodies (Wuhan Boster Biological Technology, Co., Ltd., Wuhan, China; cat. no. BA1054). The experiment was repeated in triplicate. Membranes were exposed with enhanced chemiluminescence reagent (Beyotime Institute of Biotechnology, Haimen, China) and quantified with Image $\mathbf{J}$ version 3.0 analysis software (imagej.nih.gov/ij).

Reverse transcription-quantitative polymerase chain reaction (RT-qPCR) of HSP70. Total RNA was isolated from spinal cord samples of each group using TRIzol reagent (Invitrogen; Thermo Fisher Scientific, Inc., Waltham, MA, USA). Total RNA $(1 \mu \mathrm{l})$ was used to synthesize cDNA using a TaqMan miRNA Reverse Transcription kit (Applied Biosystems; Thermo Fisher Scientific, Inc.), following treatment with DNase I for $10 \mathrm{~min}$ at $37^{\circ} \mathrm{C}$. A SYBR Green PCR Master mix (Applied Biosystems; Thermo Fisher Scientific, Inc.) and Bio-Rad iQ5 Gradient Real-Time PCR system (Bio-Rad Laboratories, Inc.) were used to perform qPCR and analyze the gene expression levels of HSP70. The thermocycling conditions were as follows: $95^{\circ} \mathrm{C}$ for $15 \mathrm{~min}$; followed by 40 cycles of $94^{\circ} \mathrm{C}$ for $15 \mathrm{sec}, 60^{\circ} \mathrm{C}$ for $30 \mathrm{sec}$ and $72^{\circ} \mathrm{C}$ for $30 \mathrm{sec}$. The HSP70 primers used for all RT-qPCR experiments were as follows: Forward, 5'-ACCAGGACACTGTTGAGTTC-3'; and reverse, 5'-ACTCATCTCCGAGTTCACAC-3'. GAPDH was used as the reference gene, with primers as follows: Forward, 5'-AAGGTGAAGGTCGGAGTCAA-3'; and reverse, 5'-AAT GAAGGGGTCATTGATGG-3'. The qPCR data was analyzed using the $2^{-\triangle \Delta C q}$ method (13).

Mitochondrial reactive oxygen species (ROS) and nicotinamide adenine dinucleotide (NADH) production. Briefly, the spinal cord samples were homogenized, and the supernatant was collected, and ROS and NADH levels measured using $10 \mu \mathrm{M}$ dichlorofluorescein diacetate (Sigma-Aldrich, St. Louis, MO, USA) for $1 \mathrm{~h}$ at $37^{\circ} \mathrm{C}$ in the dark. Mitochondrial ROS levels were detected by fluorescence measurements at $480 \mathrm{~nm}$ excitation and $530 \mathrm{~nm}$ emission wavelengths (Opsys MR; Dynex Technologies, Chantilly, VA, USA). Mitochondrial NADH levels were detected by measuring fluorescence at $360 \mathrm{~nm}$ excitation and $460 \mathrm{~nm}$ emission wavelengths.

Statistical analysis. Statistical analysis was performed using SPSS software, version 17.0 (SPSS Inc., Chicago, IL, USA). One-way analysis of variance tests were performed to compare differences between all groups, followed by least significant difference post-hoc tests. Data are presented as the mean \pm standard error. $\mathrm{P}<0.05$ was considered to indicate a statistically significant difference.

\section{Results}

Protective effects of allicin on locomotor recovery in TSCI mice. The present study investigated the effect of allicin on 
locomotor recovery in TSCI mice. The chemical structure of allicin is presented in Fig. 1. As demonstrated in Fig. 2, 1 week after TSCI, the BBB scores of TSCI mice were significantly reduced compared with the sham group $(\mathrm{P}<0.001)$. Additionally, there was a significant increase in the BBB scores following treatment with 5 or $10 \mathrm{mg} / \mathrm{kg}$ allicin compared with the TSCI model group $(\mathrm{P}=0.0023$ and $\mathrm{P}=0.0017$, respectively).

Protective effect of allicin on the spinal cord water content in TSCI mice. To confirm the effect of allicin on the spinal cord water content in TSCI mice, the current study measured the spinal cord water content following 1 week of treatment with allicin. The results are presented in Fig. 3; the spinal cord water content of TSCI mice was significantly increased compared with the sham group ( $\mathrm{P}=0.0041)$. After 1 week of allicin treatment, the mice treated with 5 or $10 \mathrm{mg} / \mathrm{kg}$ allicin exhibited a significant reduction in the spinal cord water content when compared with the percentage water content in the TSCI model group $(\mathrm{P}=0.0057$ and $\mathrm{P}=0.0032$, respectively).

Protective effect of allicin on oxidative stress in TSCI mice. To determine whether the protective effect induced by allicin was mediated by anti-oxidative activity, the enzymatic activities of CAT and SOD were measured following allicin treatment. As demonstrated in Fig. 4, the enzymatic activities of CAT and SOD were significantly reduced in the TSCI group compared with the sham group $(\mathrm{P}<0.0001$ and $\mathrm{P}=0.0001$, respectively). CAT and SOD enzymatic activities were increased by allicin treatment $(5$ or $10 \mathrm{mg} / \mathrm{kg}$ ) compared with the TSCI group $(\mathrm{P}=0.0023, \mathrm{P}=0.0014, \mathrm{P}=0.0005$ and $\mathrm{P}=0.0003$, respectively).

Protective effect of allicin on inflammation in TSCI mice. The current study also investigated the effect of allicin on the anti-inflammatory signaling pathways. The results demonstrated that the levels of NF- $\kappa \mathrm{B}$ and TNF- $\alpha$ were increased in the TSCI group compared with the sham group (each $\mathrm{P}<0.0001$; Fig. 5). Additionally, allicin treatment, at all concentrations, significantly reduced the levels of NF- $\kappa B$ and TNF- $\alpha$ compared with the TSCI model rats $(\mathrm{P}=0.0071$, $\mathrm{P}=0.0042, \mathrm{P}=0.0052, \mathrm{P}=0.0021, \mathrm{P}=0.0030$ and $\mathrm{P}=0.0016$, respectively; Fig. 5).

Protective effect of allicin on PI3K/Akt in TSCI mice. To further investigate the protective effects of allicin on TSCI, the current study investigated changes to the PI3K/Akt pathways following allicin treatment of TSCI rats. As demonstrated in Fig. 6, the protein expression levels of PI3K and the phosphorylation of Akt in TSCI mice were reduced compared with the sham group $(\mathrm{P}=0.0019$ and $\mathrm{P}=0.0006$, respectively). However, treatment with 5 or $10 \mathrm{mg} / \mathrm{kg}$ allicin significantly increased the protein expression levels of PI $3 \mathrm{~K}$ and the phosphorylation of Akt compared with the TSCI mice ( $\mathrm{P}=0.0053, \mathrm{P}=0.0022$, $\mathrm{P}=0.0036$ and $\mathrm{P}=0.0017$, respectively).

Protective effect of allicin on iNOS in TSCI mice. To investigate the mechanisms that mediate the protective effects of allicin against TSCI, iNOS protein expression in TSCI mice was measured using western blot analysis. As presented in Fig. 7, TSCI significantly increased iNOS protein expression

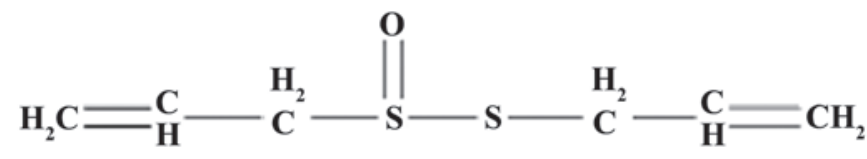

Figure 1. The chemical structure of allicin.

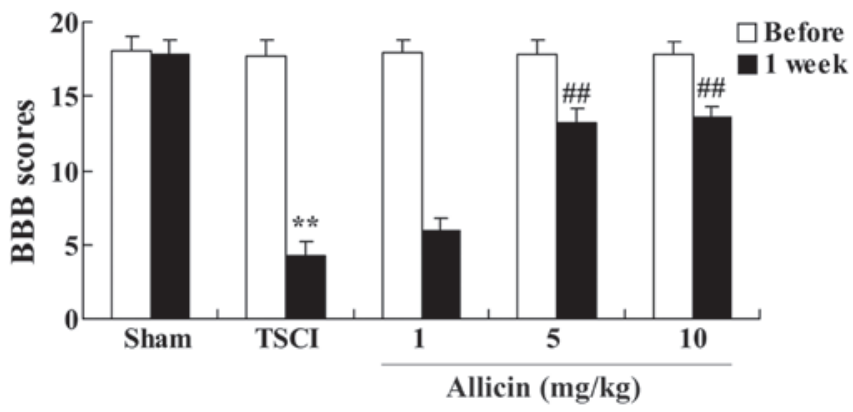

Figure 2. Protective effect of allicin on locomotor recovery in TSCI mice. BBB scores of mice in the sham, TSCI model and allicin-treated (1, 5 or $10 \mathrm{mg} / \mathrm{kg}$ ) groups. Data are presented as the mean \pm standard error. ${ }^{* *} \mathrm{P}<0.01$ vs. sham group, ${ }^{\#} \mathrm{P}<0.01$ vs. TSCI model group. BBB scores, Basso, Beattie and Bresnahan scores; TSCI, traumatic spinal cord injury.

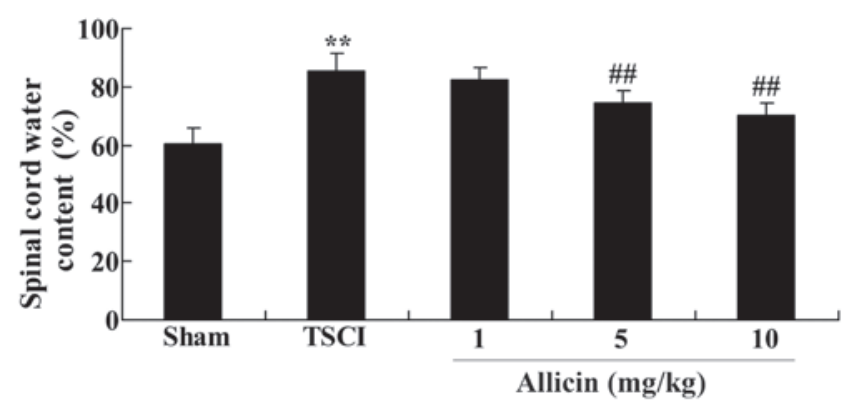

Figure 3. Protective effect of allicin on the spinal cord water content in TSCI mice. Spinal cord water content in the sham, TSCI model and allicin-treated $(1,5$ or $10 \mathrm{mg} / \mathrm{kg})$ groups. Data are presented as the mean \pm standard error. ${ }^{* *} \mathrm{P}<0.01$ vs. sham group, ${ }^{\# \#} \mathrm{P}<0.01$ vs. TSCI model group. TSCI, traumatic spinal cord injury.

compared with the sham group $(\mathrm{P}=0.0007)$. Administration of 5 and $10 \mathrm{mg} / \mathrm{kg}$ allicin significantly inhibited the promotion of iNOS protein expression compared with the TSCI model mice $(\mathrm{P}=0.0012$ and $\mathrm{P}=0.0003$, respectively).

Protective effect of allicin on HSP70 in TSCI mice. The present study also measured the HSP70 mRNA expression levels to investigate the mechanisms that mediate the effects of allicin on TSCI. As presented in Fig. 8, the HSP70 mRNA expression levels were significantly reduced in the TSCI group compared with the sham mice $(\mathrm{P}=0.0022)$. Furthermore, treatment with allicin $(5$ or $10 \mathrm{mg} / \mathrm{kg}$ ) significantly increased the HSP70 mRNA expression levels compared with the TSCI mice $(\mathrm{P}=0.0025$ and $\mathrm{P}=0.0018$, respectively; Fig. 8$)$.

Protective effect of allicin on ROS production in TSCI mice. To evaluate whether ROS are associated with the protective effect of allicin on TSCI, ROS production was measured in the experimental groups. The results of Fig. 9 demonstrate a 

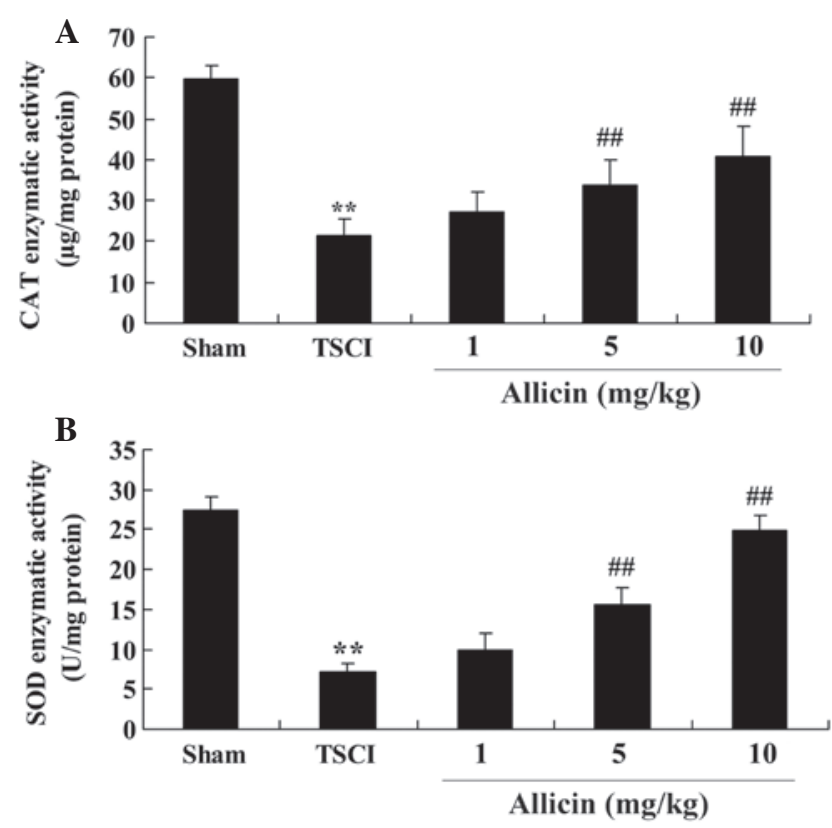

Figure 4. Protective effect of allicin on oxidative stress in TSCI mice. Protective effect of allicin on the enzymatic activities of (A) CAT and (B) SOD in the sham, TSCI model and allicin-treated $(1,5$ or $10 \mathrm{mg} / \mathrm{kg})$ groups. Data are presented as the mean \pm standard error. ${ }^{* *} \mathrm{P}<0.01$ vs. sham group, ${ }^{\# \#} \mathrm{P}<0.01$ vs. TSCI model group. TSCI, traumatic spinal cord injury; SOD, superoxide dismutase; CAT, catalase.

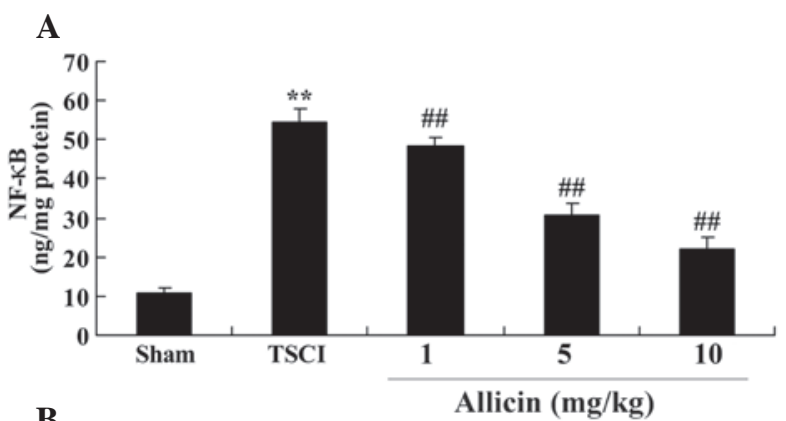

B

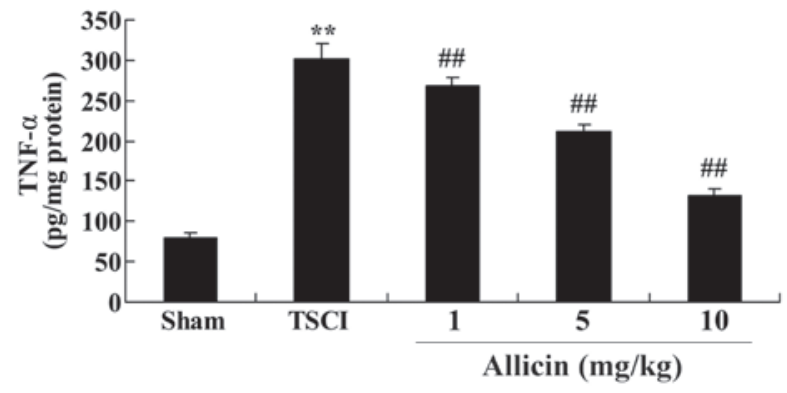

Figure 5. Protective effect of allicin on inflammation in TSCI mice. Protective effect of allicin on levels of (A) NF-kB and (B) TNF- $\alpha$ in the sham, TSCI model and allicin-treated $(1,5$ or $10 \mathrm{mg} / \mathrm{kg})$ groups. Data are presented as the mean \pm standard error. ${ }^{* *} \mathrm{P}<0.01$ vs. sham group, ${ }^{\# \#} \mathrm{P}<0.01$ vs. TSCI model

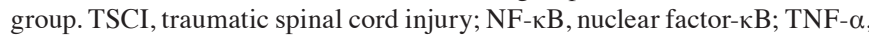
tumor necrosis factor- $\alpha$.

significant increase in ROS levels following TSCI compared with the sham group $(\mathrm{P}<0.0001)$. Notably, treatment with 5 or $10 \mathrm{mg} / \mathrm{kg}$ allicin significantly reduced the levels of ROS compared with the TSCI group $(\mathrm{P}=0.0030$ and $\mathrm{P}=0.0013$, respectively).
A
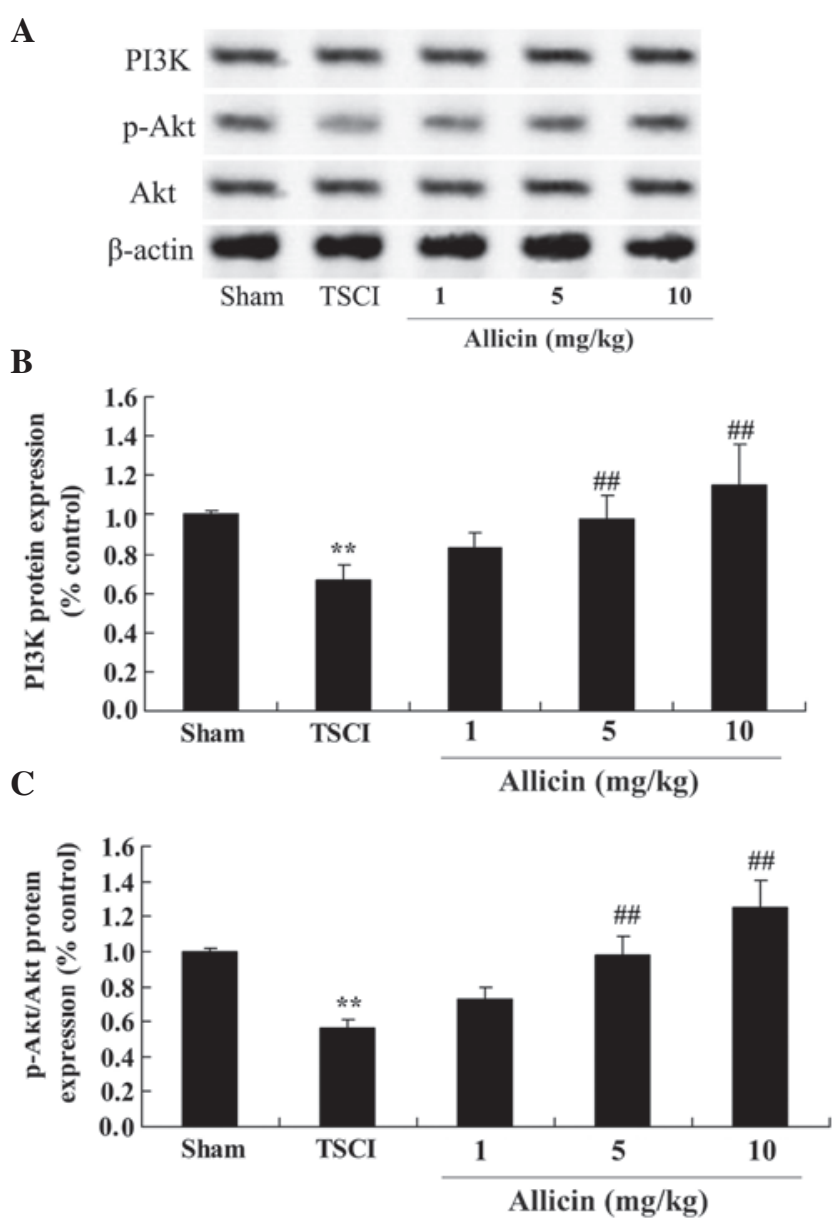

Figure 6. Protective effect of allicin on PI3K/Akt protein and phosphorylation levels in TSCI mice. (A) The effects of allicin on the PI3K/Akt and p-Akt levels were measured using western blotting. (B) Analysis of PI3K levels and (C) p-Akt/Akt in samples from the sham, TSCI model and allicin-treated $(1,5$ or $10 \mathrm{mg} / \mathrm{kg})$ groups. Data are presented as the mean \pm standard error. ${ }^{* *} \mathrm{P}<0.01$ vs. sham group, ${ }^{\# \#} \mathrm{P}<0.01$ vs. TSCI model group. TSCI, traumatic spinal cord injury; PI3K, phosphatidylinositol-4,5-bisphosphate 3-kinase; Akt, $v$-akt murine thymoma viral oncogene homolog 1 ; p-Akt, phospho-Akt.

Protective effect of allicin on NADH production in TSCI mice. To investigate the effects of allicin on NADH production in TSCI mice, the NADH levels were analyzed following TSCI and treatment with allicin. As demonstrated in Fig. 10, NADH levels were reduced in the TSCI group compared with the sham group $(\mathrm{P}=0.0007)$. However, allicin treatment (5 or $10 \mathrm{mg} / \mathrm{kg}$ ) significantly elevated the NADH levels compared with TSCI mice $(\mathrm{P}=0.0032$ and $\mathrm{P}=0.0021)$.

\section{Discussion}

The development of the transportation and construction industries has led to an increase in the number of patients suffering from traumatic TSCI (14). TSCI places a heavy burden on the families of patients and society, as the condition leads to high disability rates, high costs, loss of labor forces and other serious complications, including infection, bedsores and deep venous thrombosis (15). Certain countries have conducted numerous detailed studies on TSCI, however, few have been performed in China (15). The current study confirms the protective effect of allicin. Allicin treatment increased locomotor recovery, and 


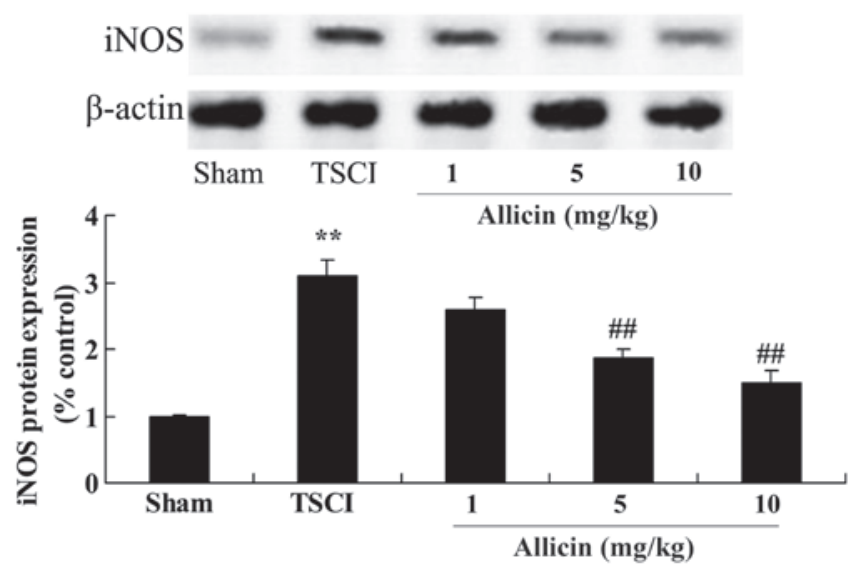

Figure 7. Effect of allicin on iNOS in TSCI mice. iNOS levels were measured in sham, TSCI model and allicin-treated $(1,5$ or $10 \mathrm{mg} / \mathrm{kg})$ groups. using western blot analysis. Data are presented as the mean \pm standard error. ${ }^{* *} \mathrm{P}<0.01$ vs. sham group, ${ }^{\# \#} \mathrm{P}<0.01$ vs. TSCI model group. iNOS, nitric oxide synthase; TSCI, traumatic spinal cord injury.

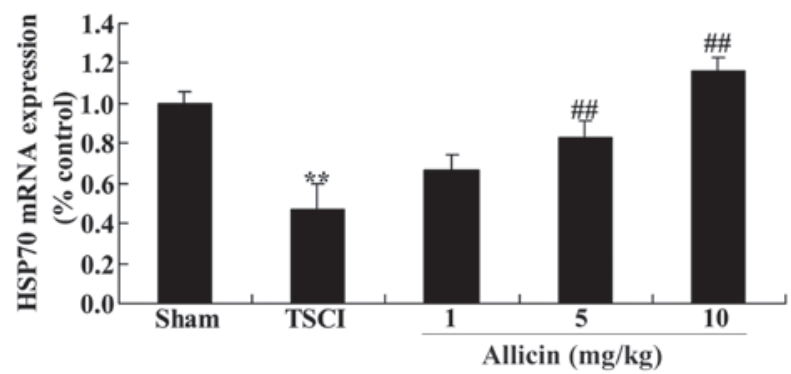

Figure 8. Effect of allicin on HSP70 mRNA levels in TSCI mice. Sham, TSCI model and allicin-treated $(1,5$ or $10 \mathrm{mg} / \mathrm{kg})$ groups. Data are presented as the mean \pm standard error. ${ }^{* *} \mathrm{P}<0.01$ vs. sham group, ${ }^{\# \#} \mathrm{P}<0.01$ vs. TSCI mode group. HSP70, heat shock protein family A member 4, TSCI, traumatic spinal cord injury.

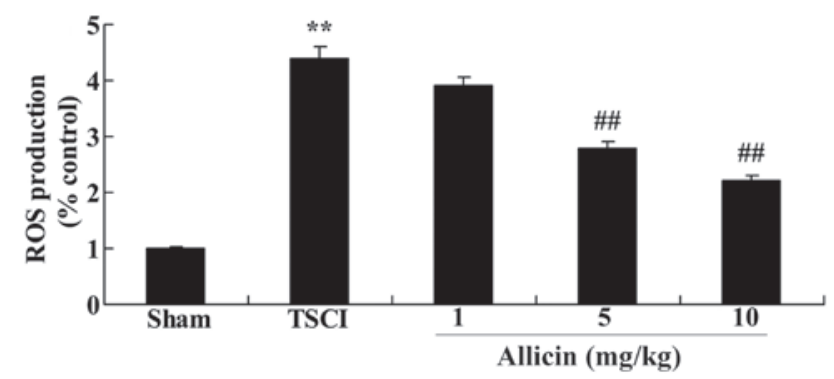

Figure 9. Effect of allicin on ROS levels in sham, TSCI model and allicin-treated $(1,5$ or $10 \mathrm{mg} / \mathrm{kg})$ mice. Data are presented as the mean \pm standard error. ${ }^{* *} \mathrm{P}<0.01$ vs. sham group, ${ }^{\#} \mathrm{P}<0.01$ vs. TSCI model group. ROS, reactive oxygen species; TSCI, traumatic spinal cord injury.

reduced the spinal cord water content, oxidative stress and inflammation in TSCI mice. Liu et al (9) reported that allicin protects spinal cord neurons via suppression of the oxidative stress pathway. Li et al (16) indicated that allicin alleviates inflammation in Caco-2 cells.

Akt is considered a vital regulatory factor for signal transduction, and together with purine signals is important in nervous physiological and pathological processes (17). Akt

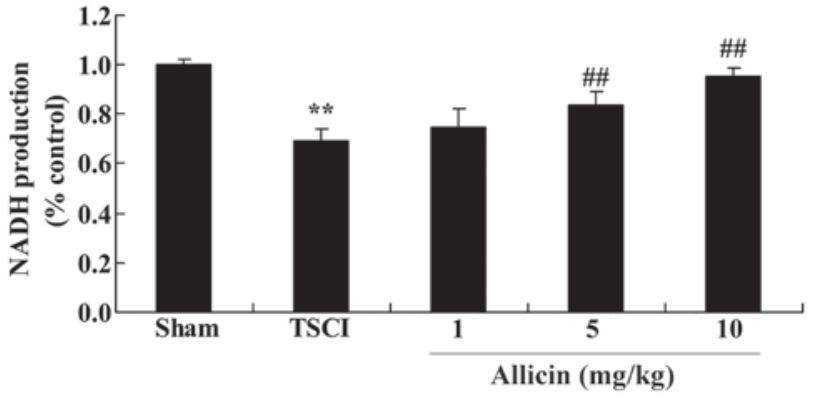

Figure 10. Effect of allicin on NADH production in sham, TSCI model and allicin-treated $(1,5$ or $10 \mathrm{mg} / \mathrm{kg})$ mice. Data are presented as the mean \pm standard error. ${ }^{* *} \mathrm{P}<0.01$ vs. sham group, ${ }^{\# \#} \mathrm{P}<0.01$ vs. TSCI model group. $\mathrm{NADH}$, nicotinamide adenine dinucleotide; TSCI, traumatic spinal cord injury.

signaling facilitates the growth, differentiation, survival and regeneration of neurons via the $\mathrm{P} 2$ receptor following injury of the central nervous system, and mediates the remodeling of impaired neural tissues (18). As a crucial mediator of protein kinase cascades, following impairment of the central nervous system, ATP can activate the PI3K/Akt pathways, which are important for the survival and repair of neurons (19). In the present study, treatment with allicin significantly increased the levels of PI3K and phospho-Akt in TSCI rats. Liu et al (20) demonstrated that allicin protects against cardiac hypertrophy and fibrosis through the activation of the ROS-dependent Akt signaling pathways.

Numerous studies have suggested that injury of the central nervous system caused by ischemia and other damage increases the expression levels of NOS $(21,22)$. Excessive NO synthesis occurs, which directly impairs the function of the nervous system. As a micromolecule and free radical, NO possesses various bioactivities, including vasodilatation, neural information transmission and cytotoxic effects (23). Excessive NO can induce cell apoptosis, which is characteristic of the secondary changes exhibited following TSCI (24). In the current study, administration of allicin significantly inhibited the promotion of iNOS protein expression in TSCI mice. Liu et al (9) reported that allicin protects spinal cord neurons through suppression of the NOS pathway. Zhou et al (25) also demonstrated that allicin protects against mechanical trauma injury via Akt- and mitogen-activated protein kinase 1-mediated regulation of the NOS pathway.

HSPs are a widely expressed, evolutionarily conserved family of proteins. They function as molecular chaperones, and are important for the transport and folding of proteins during cellular stress. HSP70 proteins are considered to be the principle family members (26). HSP70 protein expression is stimulated following stress, including heat shock, ischemia, oxygen deficit, viral infection and mechanical injuries (27). Previous studies on HSP70 in TSCI have observed that, following injury, the HSP70 protein expression levels were increased (26). In the present study, treatment with allicin significantly increased the levels of HSP70 mRNA expression in TSCI mice. Liu et al (9) previously reported that allicin protects spinal cord neurons through the regulation of the HSP70 pathway.

Numerous studies have investigated the secondary damage mechanisms following TSCI. It was previously demonstrated 
that ROS are a crucial mediator of the secondary damages caused by SCI. Following TSCI, a series of pathological changes occur in the spinal cord tissue, including edema, bleeding, anoxia and ischemia (28). These changes lead to mitochondrial dysfunction and increased of ROS production (29). In the case of the rate of ROS production exceeding the scavenging activity of the defense system, ROS accumulates in cells. In the present study, allicin significantly reduced the levels of ROS following TSCI. A previous study demonstrated that allicin protects spinal cord neurons via suppression of ROS production (9). Chan et al (30) demonstrated that allicin protects rat cardiomyoblasts by inhibiting the generation of ROS.

NADH can protect cells from injury via oxidation and peroxidation of heavy metal chromate-induced hemoglobin (31). Previous research has demonstrated that NADH can effectively eliminate oxygen free radicals, inhibit the production of ROS, stabilize the cytomembrane, activate multi-enzyme systems, and enhance the synthesis and metabolism of nucleic acids, proteins and polysaccharides. Furthermore, NADH can regulate and improve metabolism (32). Additionally, NADH is important for the production of the materials required for regeneration, repair and protection. These results demonstrate the importance of NADH as a mediator of the allicin-induced locomotor recovery of TSCI mice. The present study demonstrated that allicin significantly increased NADH production, which had been reduced by TSCI. Rabinkov et al (33) reported that the predominant biological action of allicin may be attributed to its effect on NADH levels.

In conclusion, the findings of the current study demonstrated that the beneficial effects of allicin following TSCI are mediated via the regulation of oxidative stress and inflammation. The protective effects of allicin were dependent on the promotion of HSP70 protein expression and NADH levels, and the inhibition of iNOS and ROS levels following TSCI. The results of the present study indicate that the protective effects of allicin may be useful in the treatment of TSCI.

\section{References}

1. Schwab JM, Zhang Y, Kopp MA, Brommer B and Popovich PG: The paradox of chronic neuroinflammation, systemic immune suppression, autoimmunity after traumatic chronic spinal cord injury. Exp Neurol 258: 121-129, 2014.

2. Konya D, Gercek A, Akakin A, Akakin D, Tural S, Cetinel S, Ozgen S and Pamir MN: The effects of inflammatory response associated with traumatic spinal cord injury in cutaneous wound healing and on expression of transforming growth factor-betal (TGF-beta1) and platelet-derived growth factor (PDGF)-A at the wound site in rats. Growth Factors 26: 74-79, 2008.

3. Yin KJ, Kim GM, Lee JM, He YY, Xu J and Hsu CY: JNK activation contributes to DP5 induction and apoptosis following traumatic spinal cord injury. Neurobiol Dis 20: 881-889, 2005.

4. Chan SC and Chan AP: Rehabilitation outcomes following traumatic spinal cord injury in a tertiary spinal cord injury centre: A comparison with an international standard. Spinal Cord 43: 489-498, 2005.

5. Franceschini M, Di Clemente B, Citterio A and Pagliacci MC: Follow-up in persons with traumatic spinal cord injury: Questionnaire reliability. Eura Medicophys 42: 211-218, 2006.

6. Dobkin BH, Apple D, Barbeau H, Basso M, Behrman A, Deforge D, Ditunno J, Dudley G, Elashoff R, Fugate L, et al: Methods for a randomized trial of weight-supported treadmill training versus conventional training for walking during inpatient rehabilitation after incomplete traumatic spinal cord injury. Neurorehabil Neural Repair 17: 153-167, 2003.
7. van Weert KC, Schouten EJ, Hofstede J, van de Meent H, Holtslag HR and van den Berg-Emons RJ: Acute phase complications following traumatic spinal cord injury in Dutch level 1 trauma centres. J Rehabil Med 46: 882-885, 2014.

8. Wong AM, Leong CP, Su TY, Yu SW, Tsai WC and Chen CP: Clinical trial of acupuncture for patients with spinal cord injuries. Am J Phys Med Rehabil 82: 21-27, 2003.

9. Liu SG, Ren PY, Wang GY, Yao SX and He XJ: Allicin protects spinal cord neurons from glutamate-induced oxidative stress through regulating the heat shock protein 70/inducible nitric oxide synthase pathway. Food Funct 6: 321-330, 2015.

10. Adetumbi MA and Lau BH: Allium sativum (garlic)--a natural antibiotic. Med Hypotheses 12: 227-237, 1983.

11. Borlinghaus J, Albrecht F, Gruhlke MC, Nwachukwu ID and Slusarenko AJ: Allicin: Chemistry and biological properties. Molecules 19: 12591-12618, 2014.

12. Huang W, Wang Y, Cao YG, Qi HP, Li L, Bai B, Liu Y and Sun HL: Antiarrhythmic effects and ionic mechanisms of allicin on myocardial injury of diabetic rats induced by streptozotocin. Naunyn Schmiedebergs Arch Pharmacol 386: 697-704, 2013.

13. Sieber MW, Claus RA, Witte OW and Frahm C: Attenuated inflammatory response in aged mice brains following stroke. PLoS One 6: e26288, 2011.

14. Wu Q, Ning GZ, Li YL, Feng HY and Feng SQ: Factors affecting the length of stay of patients with traumatic spinal cord injury in Tianjin, China. J Spinal Cord Med 36: 237-242, 2013.

15. Wang H, Xiang Q, Li C and Zhou Y: Epidemiology of traumatic cervical spinal fractures and risk factors for traumatic cervical spinal cord injury in China. J Spinal Disord Tech 26: E306-E313, 2013.

16. Li C, Lun W, Zhao X, Lei S, Guo Y, Ma J and Zhi F: Allicin alleviates inflammation of trinitrobenzenesulfonic acid-induced rats and suppresses P38 and JNK pathways in Caco-2 cells. Mediators Inflamm 2015: 434692, 2015.

17. Yu L, Xie J, Xin N and Wang Z: Panax notoginseng saponins promote wound repair of anterior cruciate ligament through phosphorylation of PI3K, AKT and ERK. Int J Clin Exp Pathol 8: 441-449, 2015.

18. Yune TY, Park HG, Lee JY and Oh TH: Estrogen-induced Bcl-2 expression after spinal cord injury is mediated through phosphoinositide-3-kinase/Akt-dependent CREB activation. J Neurotrauma 25: 1121-1131, 2008.

19. Jung SY, Kim DY, Yune TY, Shin DH, Baek SB and Kim CJ: Treadmill exercise reduces spinal cord injury-induced apoptosis by activating the PI3K/Akt pathway in rats. Exp Ther Med 7: 587-593, 2014.

20. Liu C, Cao F, Tang QZ, Yan L, Dong YG, Zhu LH, Wang L, Bian ZY and Li H: Allicin protects against cardiac hypertrophy and fibrosis via attenuating reactive oxygen species-dependent signaling pathways. J Nutr Biochem 21: 1238-1250, 2010.

21. Jiang Y, Gong FL, Zhao GB and Li J: Chrysin suppressed inflammatory responses and the inducible nitric oxide synthase pathway after spinal cord injury in rats. Int J Mol Sci 15: 12270-12279, 2014.

22. Abbasi Habashi S, Sabouni F, Moghimi A and Ansari Majd S: Modulation of lipopolysaccharide stimulated nuclear factor kappa B mediated iNOS/NO production by bromelain in rat primary microglial cells. Iran Biomed J 20: 33-40, 2016.

23. Ren B, Zhang YX, Zhou HX, Sun FW, Zhang ZF, Wei Z, Zhang CY and Si DW: Tanshinone IIA prevents the loss of nigrostriatal dopaminergic neurons by inhibiting NADPH oxidase and iNOS in the MPTP model of Parkinson's disease. J Neurol Sci 348: 142-152, 2015.

24. Chen M, Xia X, Zhu X, Cao J, Xu D, Ni Y, Liu Y, Yan S, Cheng X, Liu Y and Wang Y: Expression of SGTA correlates with neuronal apoptosis and reactive gliosis after spinal cord injury. Cell Tissue Res 358: 277-288, 2014.

25. Zhou YF, Li WT, Han HC, Gao DK, He XS, Li L, Song JN and Fei Z: Allicin protects rat cortical neurons against mechanical trauma injury by regulating nitric oxide synthase pathways. Brain Res Bull 100: 14-21, 2014.

26. Sharma HS, Olsson Y and Westman J: A serotonin synthesis inhibitor, p-chlorophenylalanine reduces the heat shock protein response following trauma to the spinal cord: An immunohistochemical and ultrastructural study in the rat. Neurosci Res 21: 241-249, 1995.

27. Iguchi M, Littmann AE, Chang SH, Wester LA, Knipper JS and Shields RK: Heat stress and cardiovascular, hormonal, and heat shock proteins in humans. J Athl Train 47: 184-190, 2012. 
28. Bains $M$ and Hall ED: Antioxidant therapies in traumatic brain and spinal cord injury. Biochim Biophys Acta 1822: 675-684, 2012.

29. Yeo JE,Kim JH and Kang SK: Selenium attenuates ROS-mediated apoptotic cell death of injured spinal cord through prevention of mitochondria dysfunction; in vitro and in vivo study. Cell Physiol Biochem 21: 225-238, 2008.

30. Chan JY, Tsui HT, Chung IY, Chan RY, Kwan YW and Chan SW: Allicin protects rat cardiomyoblasts (H9c2 cells) from hydrogen peroxide-induced oxidative injury through inhibiting the generation of intracellular reactive oxygen species. Int J Food Sci Nutr 65: 868-873, 2014.
31. Jin W, Ming X, Hou X, Zhu T, Yuan B, Wang J, Ni H, Jiang J, Wang $\mathrm{H}$ and Liang W: Protective effects of erythropoietin in traumatic spinal cord injury by inducing the Nrf2 signaling pathway activation. J Trauma Acute Care Surg 76: 1228-1234, 2014.

32. Lee YS, Sindhu RK, Lin CY, Ehdaie A, Lin VW and Vaziri ND: Effects of nerve graft on nitric oxide synthase, NAD $(\mathrm{P}) \mathrm{H}$ oxidase, and antioxidant enzymes in chronic spinal cord injury. Free Radic Biol Med 36: 330-339, 2004.

33. Rabinkov A, Miron T, Konstantinovski L, Wilchek M, Mirelman D and Weiner L: The mode of action of allicin: Trapping of radicals and interaction with thiol containing proteins. Biochim Biophys Acta 1379: 233-244, 1998. 